\title{
A Bibliometric Analysis and Visualisation of Research Trends in Corrosion of Titanium Implants
}

\author{
Raman Kumar ${ }^{a}$ \\ Department of Mechanical Engineering, Chandigarh University, Gharuan, Punjab, \\ India. 140413
}

Article History: Received: 11 January 2021; Accepted: 27 February 2021; Published online: 5 April 2021

\begin{abstract}
Corrosion of medical implants is a serious issue in the medical sector. The bibliometric analysis had been conducted to understand the active authors, organizations, journals, and countries involved in the research domain of "corrosion of Titanium implants". All published articles related to "corrosion of Titanium implants" from "Scopus", were analyzed using the VOS viewer to develop analysis tables and visualization maps. This article had set the objective to consolidate the scientific literature regarding "corrosion of Titanium implants" and also to find out the trends related to the same. The most active journals in this research domain were Material Science and Engineering C and Biomaterials. The most active country was the United States of America. The leading organizations engaged in the research regarding the Corrosion of Titanium implants were the Sao Paulo State University of Brazil. The most active authors who had made valuable contributions related to corrosion of Titanium implants were Jacob J.J and Zhang X.
\end{abstract}

Keywords: Titanium-implants, Corrosion, Material engineering, Bibliometric analysis, VOS viewer,

\section{Introduction}

Medical implants are manmade medical devices for replacing missing or damaged biological structures. Most of the innovations and advances in material engineering and surface engineering play a key role in developing modern implants (Ralls et al., 2020). Various types of implants had been used in modern medicine and include sensory implants, neurological implants, cardiovascular implants, orthopedic implants, contraceptive implants, and cosmetic implants. Some latest developments related to implants include bioactive glass/ bioglass coating, surface texturing, and additive manufacturing to improve the quality, life, and performance of implants (Singha, Singh and Sidhu, 2020).

Different types of metals and materials are used to create implants and the most popularly used metals and alloys for bio-implants are stainless steel, cobalt-chromium alloy, and Titanium (Novikova, 2011) (Priyanka et al., 2014). Corrosion of material of implants is a major challenge in implantation(Shaw, 2008). The major remedial measures against corrosion of implants are to bulk alloy stainless steel with Titanium and Nitrogen; bioceramic coating etc(Kamachimudali, Sridhar and Raj, 2003). The issue of corrosion of bio-implants (made of uncoated stainless steel) due to simulated body fluids of the human body is an important issue addressed in all bio implantations and Titanium Nitride coating by using physical vapor deposition method was found effective against corrosion of implantations (Iqbal et al., 2013).

There are several methods to defend corrosion of Titanium-based implants, modifying Titanium implant by electro-polymerized of 4-allyl-2-methoxyphenol (Eugenol) using direct current lower than 3.5 volts (AlMashhadani and Saleh, 2020); electrochemical deposition of hydroxyapatite post-anodizing (Almashhadani and Saleh, 2019); Plasma-sprayed, reinforced coating for improved corrosion resistance and surface Properties of Titanium-based Implants (Bansal, Singh and Sidhu, 2021); zeolite coatings against corrosion of titanium alloy biomedical implants (Bedi et al., 2009); usage of Chemical Mechanical Surface Nano-Structuring (CMNS) implementation on Titanium Based Implants (Beers, Sur and Basim, 2020); Corrosion Resistance of Boron Nitride Coated Titanium Dental Implants (Çakal et al., 2019); sol-gel coating on Titanium implants (Catauro et al., 2014);

This bibliometric analysis will be a useful platform for future researchers by realizing the top researchers, organizations, and countries involved in research regarding the corrosion of bio-implants. This article is arranged into four sections. The first section is the introduction, followed by the discussion of the methodology by which the research was conducted. The third section deals with results and discussion. The fourth section deals with the conclusion. The following research objectives and research questions were framed for conducting bibliometric analysis systematically.

\subsection{Research Objectives}

a) To consolidate the literature regarding corrosion of Titanium implants

b) To find out the trends related to research in corrosion of Titanium implants

\subsection{Research Questions}

a) Who are the active researchers working on the corrosion of Titanium implants? 
b) Which are the main organizations and countries working on the corrosion of Titanium implants?

c) Which are the main journals related to corrosion of Titanium implants?

\section{Research Methodology}

Scopus files had been used for this article. For the article selection, the Boolean used was TITLE-ABS (Titanium implant corrosion) on 04/03/2021. All the tables in this paper were created by using Microsoft Excel and VOS Viewer. Grammarly was used for spelling and grammar checks. Mendeley was used for article review and citation. This paper had been inspired by bibliometric analysis in its presentation style, analysis, and methodology from the works (Farhat et al., 2013; Liao et al., 2016; Kolkailah et al., 2019; Rodríguez-Padial et al., 2019; Tran et al., 2019; Ullah et al., 2019; Shahid et al., 2020).

\section{Results and discussion}

\subsection{Results}

This first round of search produced an outcome of 2118 documents, in nineteen languages, out of which 1193 documents were in English. The classification of document categories is shown in Figure 1. For improving the quality of the analysis, we had selected only the peer-reviewed articles and all other documents had not been considered. Thus after using filters "Article" and "English" the second round search produced an outcome of 1405 English articles (both open access and others) and had been used to conduct bibliometric analysis and visualization using VOS Viewer. The English research articles in this domain since 1964 had been shown in Figure 2.

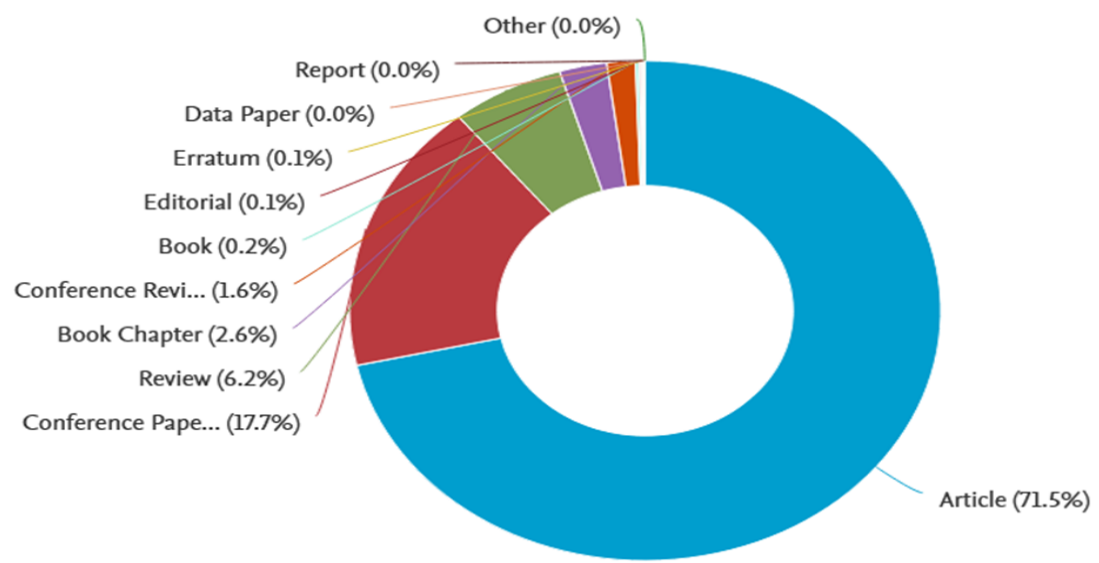

Figure 1: Classification of the documents on "Corrosion of Titanium implants", Source: www.scopus.com

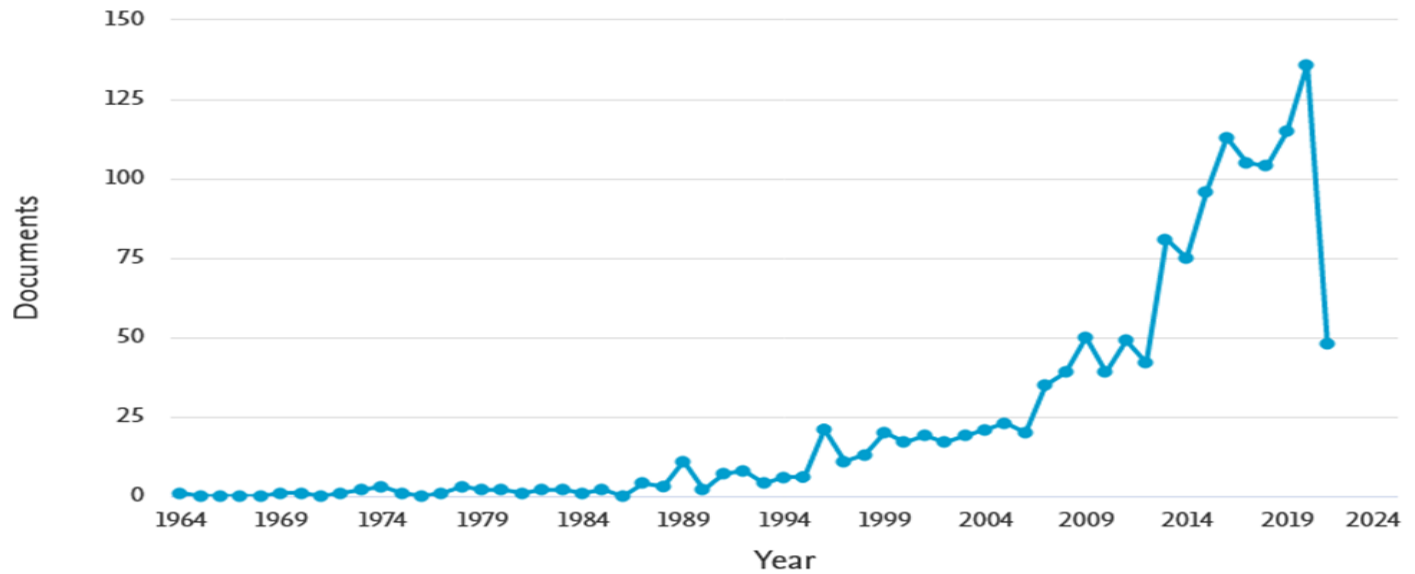

Figure 2: Period wise publication of articles, Source: WWW.scopus.com

Co-authorship analysis of top authors had been shown in figure 3. For a better presentation of the analysis, the parameters used were the minimum number of documents of an author as nine and the minimum number of citations of authors as one. This combination plotted the map of 31 authors, in seven clusters. The overlay visualization map of co-authorship analysis plotted in Figure 3, points out the major researchers with their strong co-authorship linkages and clusters involved. 


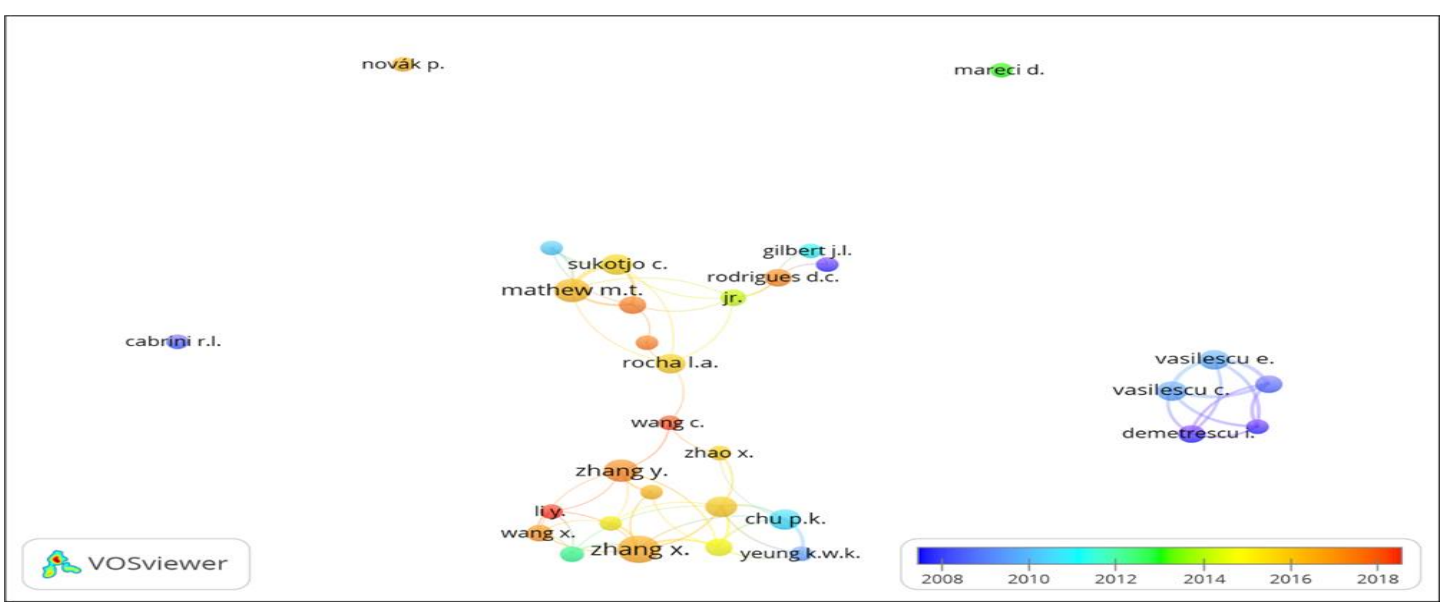

Figure 3: Co-authorship analysis on basis of authors

The citation analysis of top authors had been shown in table 1, along with co-authorship links. For the citation analysis, the parameters used were the minimum number of documents of an author as one and the minimum citations of an author as one.

Table 1: Highlights of most active authors

\begin{tabular}{|c|r|r|r|r|r|}
\hline Description & Authors & Documents & Citations & $\begin{array}{c}\text { Average } \\
\text { citations per } \\
\text { documents }\end{array}$ & $\begin{array}{c}\text { Link } \\
\text { strength }\end{array}$ \\
\hline $\begin{array}{l}\text { Authors with the } \\
\text { highest publication } \\
\text { and co-authorship } \\
\text { links }\end{array}$ & Zhang X. & 31 & 1042 & & \\
\hline $\begin{array}{l}\text { Authors with the } \\
\text { highest citations }\end{array}$ & Jacobs J.J & 09 & 2144 & & \\
\hline
\end{tabular}

In Co-occurrence analysis, we had used all keyword analyses, by keeping the minimum number of occurrences of a keyword as 100. This combination plotted the map of 43 thresholds, in two clusters. The overlay visualization of co-occurrence analysis of keywords has been shown in Figure 4.

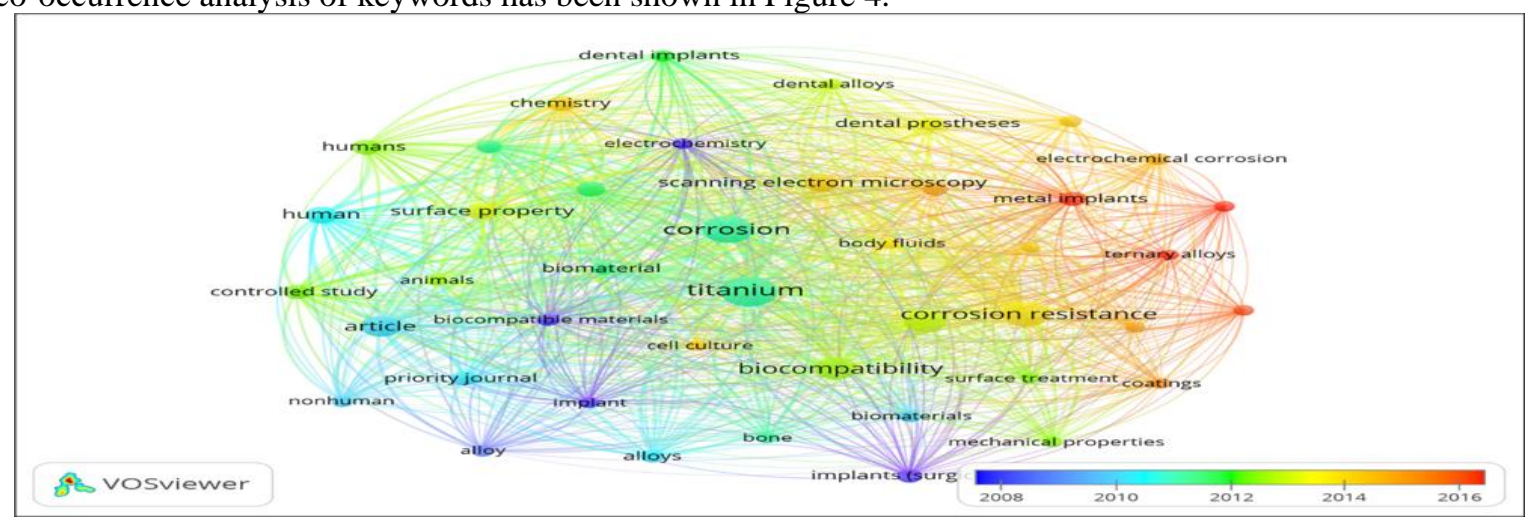

Figure 4: Co-occurrence analysis on basis of all keywords

The leading organizations engaged in research on "Corrosion of Titanium implants" had been found out by the volume of publications and citation analysis, the parameters used are the minimum number of documents of an organization as one and the minimum number of citations of organizations as one. The leading organization in the research regarding "Corrosion of Titanium implants", with the highest number of publications and citations, was the Sao Paulo State University of Brazil. (Refer to table 2).

Table 2: Highlights of the most active organization

\begin{tabular}{|c|c|c|c|c|}
\hline Organizations & Country & s & Document & $\begin{array}{l}\text { Citatio } \\
\text { Average } \\
\text { Citations } \\
\text { per } \\
\text { document }\end{array}$ \\
\hline Sao Paulo State University & Brazil & 52 & 1049 & 20.1 \\
\hline
\end{tabular}


Co-authorship analysis of the countries engaged in the research on "Corrosion of Titanium implants" had been shown in Figure 5. The overlay visualization map of co-authorship analysis plotted in Figure 5, points out the main countries with their strong co-authorship linkages and clusters involved.

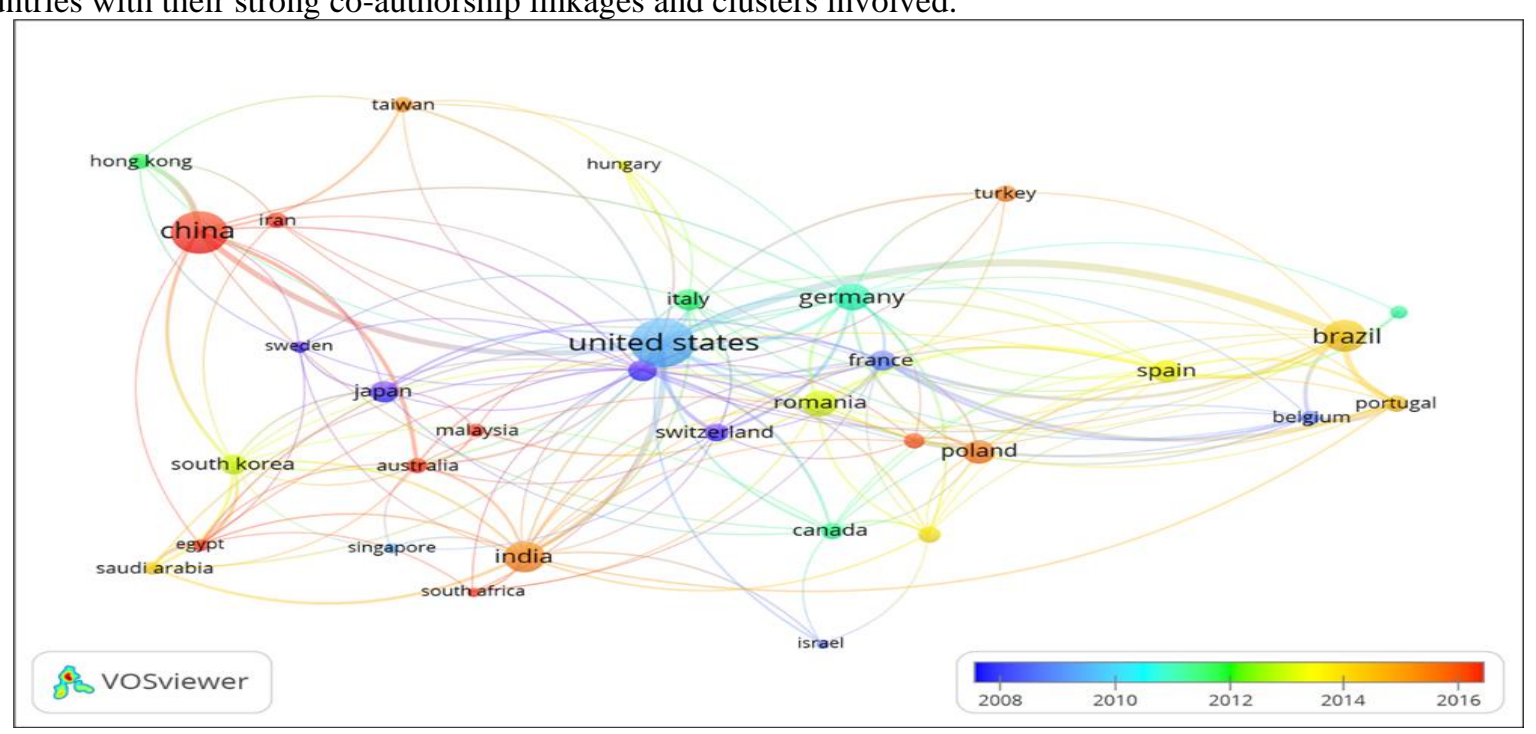

Figure 5: Co-authorship analysis on basis of countries

The citation analysis of top countries had been shown in table 3, along with co-authorship links. For the citation analysis, the parameters used were the minimum number of documents of a country as one and the minimum citations of the country as one.

Table 3: Highlights of Active Countries

\begin{tabular}{|c|c|c|c|c|}
\hline Description & Country & Document & Citation & Link strength \\
\hline $\begin{array}{c}\text { The country with the } \\
\text { highest publication, citations, } \\
\text { and co-authorship links }\end{array}$ & $\begin{array}{c}\text { United States of } \\
\text { America }\end{array}$ & 269 & 10513 & 147 \\
\hline
\end{tabular}

The most active country in this research domain was the United States of America, with the highest number of publications, and citations.

Link analysis and citation analysis were used to identify the most active journal in this research domain. We have taken the parameters of the minimum number of documents of a journal as one and the minimum number of citations of a journal as one for the link analysis and citation analysis. Highlights of the most active and relevant journals related to "Corrosion of Titanium implants" are shown in table 4 . Table 4 shows the journal activity of this research domain through parameters of publication volume, citations, and co-authorship linkages.

Table 4: Analysis of journal activity

\begin{tabular}{|c|r|r|r|r|}
\hline Description & Journal details & Documents & Citations & $\begin{array}{c}\text { Average } \\
\text { citations } \\
\text { per } \\
\text { documents }\end{array}$ \\
\hline $\begin{array}{c}\text { Journal with the } \\
\text { highest publications }\end{array}$ & $\begin{array}{c}\text { Material Science } \\
\text { and Engineering C }\end{array}$ & 65 & 1569 & 176 \\
\hline $\begin{array}{l}\text { Journal with the } \\
\text { highest citation and co- } \\
\text { authorship links }\end{array}$ & Biomaterials & 29 & 4169 & 267 \\
\hline
\end{tabular}

From the above discussion regarding the bibliometric patterns in the research regarding Corrosion of Titanium implants, this research had observed a gradual increase in research interest regarding Corrosion of Titanium implants from the starting of the millennium and the momentum is going on positively. This points out the relevance and potential of this research domain (Refer to Figure 2). The most active authors in this research domain were Jacob J.J and Zhang X. with the highest citations; publication and co-authorship links respectively (Refer to table 1). The overlay analysis of top countries researching corrosion of Titanium implants indicates that the United States of America was the leading country relating to the highest number of publications, citations, and coauthorship links (Refer to figure 5). The top journal of this research domain was identified as the Material Science and Engineering $\mathrm{C}$ and Biomaterials. From these wide sources of information, researchers can focus on top journals where they can identify the most relevant and highly cited articles regarding the Corrosion of Titanium implants. 


\section{Conclusion}

Corrosion of Titanium implants was an interesting research domain and the most active journal related to this research domain were Material Science and Engineering $\mathrm{C}$ and Biomaterials. The most active country was the United States of America. The leading organization engaged in the research regarding the Corrosion of Titanium implants was the Sao Paulo State University of Brazil. The most active authors who had made valuable contributions related to corrosion of Titanium implants were Jacob J.J and Zhang X. This research domain offers a new avenue for researchers and future research can be on innovations in the Corrosion of Titanium implants.

\section{References}

1. Almashhadani, H. A. and Saleh, K. A. (2019) 'Corrosion protection of pure titanium implant by electrochemical deposition of hydroxyapatite post-anodizing', in IOP Conference Series: Materials Science and Engineering. Institute of Physics Publishing. doi: 10.1088/1757-899X/571/1/012071.

2. AlMashhadani, H. A. and Saleh, K. A. (2020) 'Corrosion protection of pure titanium implant in artificial saliva by electro-polymerization of poly eugenol', Egyptian Journal of Chemistry, 63(8), pp. 2803-2811. doi: 10.21608/ejchem.2019.13617.1842.

3. Bansal, P., Singh, G. and Sidhu, H. S. (2021) 'Plasma-Sprayed HA/Sr Reinforced Coating for Improved Corrosion Resistance and Surface Properties of Ti13Nb13Zr Titanium Alloy for Biomedical Implants', Journal of Materials Research. doi: 10.1557/s43578-020-00044-x.

4. Bedi, R. S. et al. (2009) 'Biocompatibility of corrosion-resistant zeolite coatings for titanium alloy biomedical implants', Acta Biomaterialia, 5(8), pp. 3265-3271. doi: 10.1016/j.actbio.2009.04.019.

5. Beers, K., Sur, D. and Basim, G. B. (2020) 'Chemical Mechanical Surface Nano-Structuring (CMNS) Implementation on Titanium Based Implants to Enhance Corrosion Resistance and Control Biocompatibility', MRS Advances. doi: 10.1557/adv.2020.325.

6. Çakal, G. Ö. et al. (2019) 'Surface Characterization and Corrosion Resistance of Boron Nitride Coated Titanium Dental Implants', Protection of Metals and Physical Chemistry of Surfaces, 55(3), pp. 608-614. doi: $10.1134 /$ S2070205119030079.

7. Catauro, M. et al. (2014) 'Corrosion behavior and mechanical properties of bioactive sol-gel coatings on titanium implants', Materials Science and Engineering C, 43, pp. 375-382. doi: 10.1016/j.msec.2014.07.044.

8. Farhat, T. et al. (2013) 'Research in congenital heart disease: A comparative bibliometric analysis between developing and developed countries', Pediatric Cardiology, 34(2), pp. 375-382. doi: 10.1007/s00246-012-0466-6.

9. Iqbal, W. et al. (2013) 'Corrosion behavior of coated and uncoated bio implants in SBF (simulated body fluid)', Journal of the Chemical Society of Pakistan, 35(3), pp. 663-665.

10. Kamachimudali, U., Sridhar, T. M. and Raj, B. (2003) 'Corrosion of bio implants', Sadhana, 28(3), pp. 601-637. doi: 10.1007/BF02706450.

11. Kolkailah, A. A. et al. (2019) 'Bibliometric Analysis of the Top 100 Most Cited Articles in the First 50 Years of Heart Transplantation', American Journal of Cardiology, 123(1), pp. 175-186. doi: 10.1016/j.amjcard.2018.09.010.

12. Liao, J. et al. (2016) 'The most cited articles in coronary heart disease: A bibliometric analysis between 1970 and 2015', International Journal of Cardiology, 222, pp. 1049-1052. doi: 10.1016/j.ijcard.2016.08.002.

13. Novikova, G. E. (2011) 'Introduction to corrosion of bioimplants', Protection of Metals and Physical Chemistry of Surfaces, 47(3), pp. 372-380. doi: 10.1134/S2070205111030105.

14. Priyanka, P. et al. (2014) Role of nanogrooves on the performance of ultra-fine grained titanium as a bioimplant, Advanced Nanomaterials: Synthesis, Properties, and Applications. Apple Academic Press. doi: $10.1201 / \mathrm{b} 16966$.

15. Ralls, A. et al. (2020) 'Material Design and Surface Engineering for Bio-implants', JOM, 72(2), pp. 684696. doi: 10.1007/s11837-019-03687-2.

16. Rodríguez-Padial, L. et al. (2019) 'Trends and Bibliometric Impact of Research Grants of the Spanish Society of Cardiology/Spanish Heart Foundation (2007-2012) [Evolución e impacto bibliométrico de las becas de la Sociedad Española de Cardiología/Fundación Española del Corazón en el periodo', Revista Espanola de Cardiologia, 72(12), pp. 1012-1019. doi: 10.1016/j.recesp.2018.08.013.

17. Shahid, I. et al. (2020) 'Characteristics of highly cited articles in heart failure: A bibliometric analysis', Future Cardiology, 16(3), pp. 189-197. doi: 10.2217/fca-2019-0016.

18. Shaw, B. A. (2008) 'Corrosion within the human body: Prospects and problems with bioimplants', Electrochemical Society Interface, 17(2), p. 29.

19. Singha, B., Singh, G. and Sidhu, B. S. (2020) 'Current Trends in Bio-I mplants ' Research', The Research Publication, 7(2), pp. 57-59.

20. Tran, B. X. et al. (2019) 'The current research landscape of the application of artificial intelligence in managing cerebrovascular and heart diseases: A bibliometric and content analysis', International Journal of Environmental Research and Public Health, 16(15). doi: 10.3390/ijerph16152699. 
21. Ullah, S. et al. (2019) 'Publication trends of Pakistan Heart Journal: A bibliometric study', Library Philosophy and Practice, 2019. 